\title{
The Media Genre of the Personal Account: RHETORICAL AND Linguistic ConstruCtion of The Socio-Cultural Setting
}

\begin{abstract}
Genre studies are of high relevance to media discourse in general and women's magazines discourse in particular if one considers their pervasiveness in our lives. This study presents a genre analysis of the personal account, endemic in women's magazines. The paper identifies the generic structure of the personal account and the rhetorical strategies of its textual implementation. More specifically, it focuses on the rhetorical strategies of the first element of the generic structure, the Summary and Orientation move, and on its most conspicuous linguistic features. The paper examines how the conventions of the move participate in the construction of the socio-cultural setting of the personal account. The study utilizes personal accounts from The Cosmopolitan, which was chosen due to its global international status and general thematic orientation.
\end{abstract}

\section{Key words}

Genre; personal account; generic structure; move; rhetorical strategy

\section{Introduction}

Women's magazines are one of the most popular media and even the least frequent of readers are aware of their ubiquity. The popularity and variety of women's magazines increasingly make them the objects of sociological and cultural studies ${ }^{1}$ which have shown an important role of these media in the maintenance of cultural values by addressing their audience as a "single unified community by virtue of its femaleness" (Ferguson 1983: 6). The relationship between the language of women's magazines and their construction of community has been 
extensively studied in recent years. The studies have demonstrated a close relationship between the language and the hegemonic model identity promoted by women's magazines in terms of gender, sexuality, human relations, etc. (CaldasCoulthard 1996, Figueiredo 2009). They have also revealed how a particular use of lexis contributes to the self-distinction of the magazine (Hermes 1995, Craviotto 2006), what strategies are used by women's magazines in their attempt to construct the readership community (Tomášková 2009), and how multimodal realization of magazine's discourse enables women to signify their alignment with the world of the magazine (Machin et al 2003).

Despite the variety of approaches undertaken to study the problem, few investigations have focused on the genre approach to the language of women's magazines, even though genre analysis "gives a rich source of discovery not only about the ways media texts are constructed, but also about the ways they are likely to be interpreted, used and exploited in specific contexts to achieve specific goals" (Bhatia 2004: 23). For this reason, it would be of interest to study one of the genres exploited by women's magazines and to unveil its role in constructing the community of the magazine and delivering the community values to the audience as well as the ways in which the values are enacted by the language of the genre. Using genre approach, this study explores the genre of the personal account, endemic in women's magazines. Although personal accounts in women's magazines have already been researched from different methodological standpoints (Caldas-Coulthard 1996, Segal 2007, Figueiredo 2009), few attempts have been made to investigate them within a paradigm of linguistics.

The paper explores the generic structure of the personal account. More specifically, it focuses on its first element - the Summary and Orientation move - which comprises the headline and the sub-headline of personal accounts. The paper examines how conventional features of this move participate in the construction of the socio-cultural setting of the genre in question. The study addresses the following research problems: 1) general approach to the personal account as a media genre; 2) generic structure of personal accounts; 3) rhetorical strategies of the Summary and Orientation move and the key linguistic features of their implementation; 4) schematic structure of the Summary and Orientation move and its role in fulfilling the overall purpose of the genre.

A multi-perspective analysis of the Summary and Orientation move provides a detailed picture by describing the linguistic characteristics of the move constituents - headlines and sub-headlines. The study is theoretically framed by Swales' (1990) genre analysis, Labov's (1972) model of narration and functional stylistic approach to language.

\section{Genre approach: theoretical framework for the present study}

The concept of genre has been a matter of considerable attention in research communities throughout the world. The literature on genre of the last 30 years boasts 
a number of perspectives that have become widely accepted: genre as a typified rhetorical and social action (Miller 1994), as a goal-oriented social process (Martin 1985) and as a communicative event in the context of social practice (Swales 1990). From the integrated perspective, Bhatia (2004: 23) defines genre as "essentially referring to language in a conventionalized communicative setting in order to give expression to a specific set of communicative goals of social institution". By linking communicative purposes and social processes, these approaches to genre share common ground. One of the most extensive definitions of the genre concept is that of Swales (1990: 58):

A genre comprises a class of communicative events, the members of which share some set of communicative purposes. These purposes are recognized by the expert members of the parent discourse community and thereby constitute the rationale for the genre. This rationale shapes the schematic structure of the discourse and influence and constrains choice of content and style.

As it follows from the definition, the primary criterion for identifying certain communicative events as a "genre" is a set of shared communicative purposes understood and accepted by the members of the community in which the genre regularly occurs. The members of any community are generally credited with the knowledge of not only the communicative goals of their community but also of the structure of the genres in which they participate as part of their daily life (Bhatia 2004), that is, to fully understand genres it is important to understand the culture in which they are embedded. In this sense, genre is regarded "as part of social process by which knowledge and facts are made, a recurrent, significant action that embodies an aspect of cultural rationality" (Miller 1994: 39). In other words, genres not only respond to particular discourse community but also shape and, in a way, stabilize it.

The communicative purpose as "the rationale for genre" shapes the genre and determines its internal structure. Therefore, genres are structured and conventionalized. The interaction of a social purpose with a performed social activity leads to the creation and unfolding of particular texts with a hierarchical schematic structure. Genre, therefore, becomes a model, or a scheme, since through its normativity and regularity it serves as an example for constructing new texts of the same kind (Yakhontova 1997: 85). One of the goals of genre analysis is to identify the schematic organization of texts belonging to a given genre. Based on this notion, the terms "move" and "step" were suggested to refer to textual units of analysis (Swales 1990). A "move" refers to a text segment that performs a particular communicative function, and a "step" is a sub-unit of a move that, in turn, contributes to the move's communicative function. Another term that refers to the way the writer adopts to execute the move is "strategy". According to Bhatia (2004), in order to realize a particular communicative intention at the level of a move, an individual writer may use different rhetorical strategies. 
Hence, "step" and "rhetorical strategy" have the same meaning and are subordinate to "move".

A move can be defined as a semantic and functional unit that associates with the writer's purpose and contributes, in some way, to fulfilling the overall purpose of the genre. The purposive nature of a move triggers a range of conventionalized verbal and visual rhetorical strategies used to realize its particular communicative intention. Although there is no absolute correlation between a certain move and its verbal and visual implementation, moves can be recognized by a certain set of co-occurring linguistic features.

To conclude, the general aim of genre analysis is to identify the moves, rhetorical strategies, the order of moves, their key linguistic features, and to reveal their connection with socio-cultural roots of the genre in question, that is to explain why these features are employed by expert users of the genre.

\section{The media genre of the personal account: discourse community and generic conventions}

Women's magazines are highly popular mass media products. Their attractiveness is based on the fact that they explore problems typically faced by women, providing the information in a colorful and easy-to-process way. The pleasure of reading women's magazines is the medium through which ideological meanings are conveyed. As McCracken (1993: 3) says, "women's magazines exert a cultural leadership to shape consensus in which highly pleasurable codes work to naturalize social relation of power". For Winship (1987: 35), "magazines sell women a representation of femininity that shapes the social place of women". In this way, these popular media function as "manuals" of womanhood: tell women who to be, what to know and how to behave, creating a "cult" of femininity.

Perpetuating the myth of femininity, women's magazines position themselves as friends, advisors and instructors in the process of carrying out the task of being a modern woman (Ferguson 1983). The woman is addressed as already "a woman", which is the ground on which she is identified as a reader. The female reader of a certain magazine is uniform in terms of age, social class, visual image, mentality and most notably, interests. A set of images and representations constructs an ideal reader suggesting no differences within this firmly established uniformity. The uniformity of participants provide a discourse in which a sense of community and shared interest is established through a variety of tools, ranging from genre forms adopted by magazines to their intimate and friendly language style (Ballaster et al. 1991, Hermes 1995) or the use of specific vocabulary (TesoCraviotto 2006). The imitation of solidarity and friendship makes readers feel comfortable and constructs a friendly agreement regarding basic presuppositions of what it means to be a woman.

Claiming solidarity and friendship, women's magazines however, assert their authority. The "expert" status within the community belongs to the "high priest- 
esses" - editors, journalists, entrepreneurs - who select, shape and carry messages, "sacred to the cult of femininity" (Ferguson 1983: 5). Journalists typically choose a particular "frame," or point of view, in discussing events and issues. The presence of fixed "frames" creates certain expectations and helps to build a loyal readership.

Women's magazines have established an effective mechanism of intercommunication within their community. They employ a set of specific genres to maintain contact with their readers and further the community's aims. One of endemic and popular genres is the personal account (some authors also refer to it as "narrative" or "personal narrative" (Caldas-Coulthard 1996, Segal 2007)). The communicative purpose of this genre is to inform readers about a solution of a certain problem on the basis of a story narrated by a woman and arising from her personal experience on the topic of potential interest to the audience of women's magazines. The increasing public demand for self-exposure and the desire for an insight into the private lives of others are only the preliminary reasons of genre's popularity. The primary one can be defined by the specific features of the readership with their "natural lounge for sharing feelings and experiences as a way of escaping solitude" (Ballaster et al 1991: 131).

In terms of the method of collecting information, the personal account is based on an open-ended question on a certain topic informally asked by an interviewer, which allows the respondent to answer freely and in depth ${ }^{2}$. Such a method of collecting information develops informal and friendly interpersonal relations of the participants. It involves trust which generates more personal information about the respondent's interpretation of the world and flexibility since the conversation is not constrained by questions prepared in advance. In this way it provides more opportunity for the respondents to say what they want rather than what the interviewer expects.

In terms of genre, the personal account presents the interviewer as an "invisible" actor by mentioning her presence only once (as will be shown in Section 6.2). Personal accounts are viewed as stories presented by "real" readers, however the influence of interviewer's / editor's voice, position and the institutional point of view can be traced in the peculiarities of the story's frame. The process of framing and filtering of "real" reader's voice by the voice of an editor makes personal accounts similar to other media genres, while the peculiarities of the "frame" make the definition and recognition of this genre distinct and clear.

The personal account as a media genre has the following basic characteristics: 1) the information is provided from the first-person point of view; 2) an experience (event) is presented as a special occurrence, something which is not a part of everyday routine; 3 ) the story follows the structure of narratives of personal experience suggested by Labov (1972); 4) the texts of personal accounts possess a distinct "look" that differentiates them from the range of other genres on vivid and colorful pages of women's magazines.

Like other media genres, the personal account comprises verbal and visual elements. Its layout structure is presented by the headline, the sub-headline ${ }^{3}$ (which 
contextualizes the personal story in question), the body of the personal account and photos that illustrate the narrated experience. A special "look" of the genre is created by the photos and quotation marks that accompany its textual manifestations. The images of women telling their stories differ from gorgeous seductive images of models and celebrities. These women look more "real" since they are positioned in their natural environment which differs strongly from the fictive world of advertisements. Quotation marks, graphically emphasized, indicate the beginning and the end of the story and focus on the personal perspective.

The first-person point of view is considered to be the most reader-friendly, as it is intimate. As Bruner (2004: 701) argues, the "exclusively private and intimate information is "voiced" through the practice of personal narratives". The firstperson perspective allows approaching the issues that cannot possibly be discussed by means of any other genre due to their intimate and personal character. Trust and friendliness of women confiding their experience in personal accounts are supposed to be shared by readers and, thus, imply a feeling of friendship and a sense of community.

Personal accounts concern different spheres of woman's life, but their insight into the private life of others makes them especially appealing. The notion of event, the basis of storytelling (Labov 1972), may be defined as the one that is least likely to have occurred and has the greatest effect on the life of a woman sharing her experience. The newsworthy status of the events enables them to function as a coordinating mechanism between the values and priorities promoted by women's magazines and the ones shared by their readers.

The personal account is a highly structured genre. It generally follows the structure of oral narratives of personal experience suggested by Labov (1972) and includes the following elements: 1) summary, which introduces and summarizes the story; 2) orientation, which sets the scene and characters; 3) complicating actions, which describe what happened next; 4) resolution, which tells what finally happened; 5) coda, which returns the verbal perspective to the present. These clauses are interspersed with evaluative clauses which bring out the significance and relevance of the elements of the story to the narrator and listeners. The conventional structure of personal accounts reflects a natural and familiar way of presenting experience and sufficiently meets readers' expectations.

To sum up, the generic conventions of the personal account reflect the communicative purpose of the genre. However, a deeper insight into the organization of this genre can reveal a set of rhetorical strategies which make this genre function in an effective and efficient way.

\section{Methodology}

The analyzed corpus consists of fifty texts of personal accounts, of which twenty five were collected from the print version of The Cosmopolitan UK over the years of 2007-2008, and twenty five - from the online version of The Cosmopolitan US 
(2014-2015). The choice of The Cosmopolitan is dictated by the global international status of the magazine, its general thematic orientation and the author's personal preference.

The collected texts were chosen at random and concern different spheres of female activity. Being included into the almost every issue of the magazine, they demonstrate the popularity and success of this media genre and, consequently, appear to be worthy of investigation. Despite the time gap between the two subcorpora, possible national variations and the peculiarities of online and printed versions, the collected texts obviously share some similar syntactical and stylistic features (as will be shown in Section 6). Given these similarities, they are organized into one corpus, so that the degree of universality of generic features of personal accounts can be traced and evaluated.

Genre approach to the texts of personal accounts allows revealing their generic move structure and, in our case, the schematic structure of Summary and Orientation - the first move of the personal account. To solve the problem of move identification, the elements of Labov's (1972) model of narration were used. Although Labov's model did not originate within the field of genre studies, it was developed based on the analysis of oral narratives of personal experience using the material gained in interviews as part of socio-linguistic research into vernacular language of New Yorkers. Labov's elements of the narrative structure can be considered as the basis for textual organization of the genre under analysis. The term "move" (Swales 1990), typical of genre analysis, is used to refer to the elements of Labov's model. The transition of the notion of "element" from Labov's model into the notion of Swales' "move" can be helpful to interpret the genre, revealing why and how the move was employed to construct the texts of personal accounts in The Cosmopolitan.

The paper also makes use of a functional stylistic approach, developed within East European linguistic context, to the analysis of key linguistic features of the Summary and Orientation move. Within this methodological paradigm, various linguistic means are analyzed from the viewpoint of their functional role in the construction of the socio-cultural setting of the genre.

The procedure for the analysis of the collected texts arises from the current vision of the concept of genre (described in Section 2) and involves identifying the generic structure of the personal account and the rhetorical strategies of its textual implementation. More specifically, the paper will focus on the rhetorical strategies of the first element of the generic structure, the Summary and Orientation move, and, further, on its most conspicuous linguistic features. Finally, the paper will examine how the conventions of the move participate in the construction of the socio-cultural setting of the personal account. 


\section{The generic structure of the personal account}

The research has shown that the personal account has a particular organizational pattern consisting of four moves which provides a distinct structure to the story narrated. The moves generally correspond to the elements of the structural model of oral narratives suggested by Labov (1972):

Move 1- Summary and Orientation (What is the story about? Who, when, where, what?)

Move 2 - Complicating Action (Then what happened?)

Move 3 - Evaluation and Resolution (How is this interesting? What finally happened?)

Move 4 - Coda (That's it, I've finished).

The personal account is a highly structured genre since there are no variations in the sequence of its moves: they are recurrent and obey the same order in all 50 samples $(100 \%)$ of the corpus. A typical example of the generic and textual structures of the personal account is provided in Table 1.

Table 1. Generic and textual structure of the personal account

\begin{tabular}{|c|c|c|}
\hline $\begin{array}{l}\text { Generic } \\
\text { structure }\end{array}$ & $\begin{array}{l}\text { The media genre of the personal account } \\
\text { (sample) }\end{array}$ & $\begin{array}{c}\text { Textual } \\
\text { structure }\end{array}$ \\
\hline Move 1 & “The story I'm ready to tell" & The headline \\
\hline $\begin{array}{l}\text { Summary and } \\
\text { Orientation }\end{array}$ & $\begin{array}{l}\text { Onscreen, Dallas and } 90210 \text { star AnnaLynne McCord } \\
\text { radiates confidence. But before she found TV success, } \\
\text { she survived a strict, violent upbringing and sexual as- } \\
\text { sault by a friend. Now she's speaking out to help other } \\
\text { women who don't have a voice. }\end{array}$ & $\begin{array}{l}\text { The sub- } \\
\text { headline }\end{array}$ \\
\hline $\begin{array}{l}\text { Move } 2 \\
\text { Complicating } \\
\text { Actions }\end{array}$ & $\begin{array}{l}\text { I grew up in an extremely religious and conservative } \\
\text { family in Georgia.... My dad was a nondenominational } \\
\text { Christian pastor. ... We never talked about sex.... My } \\
\text { parents believed in strict "discipline", as they called it - } \\
\text { I would call it abuse. ... I knew my mum and dad loved } \\
\text { me, and I loved them too. ... It really messed me up... }\end{array}$ & The body \\
\hline $\begin{array}{l}\text { Move } 3 \\
\text { Evaluation } \\
\text { and Resolu- } \\
\quad \text { tion }\end{array}$ & $\begin{array}{l}\text { I began challenging my experience into something } \\
\text { good. I met dozens of young survivors. They became } \\
\text { my friends, my sisters. Through helping them heal, } \\
\text { I began to heal myself. }\end{array}$ & \\
\hline $\begin{array}{c}\text { Move } 4 \\
\text { Coda }\end{array}$ & $\begin{array}{l}\text {... Most of all I have a message for women and girls. } \\
\text { You have a voice. Don't put yourself in a box. Don't let } \\
\text { the polite lies of society silence you (September 2014). }\end{array}$ & \\
\hline
\end{tabular}


The table gives an idea of the typical development of the personal account. It shows the presence of all moves and their correspondence to the textual structure of the genre. As seen from the table, move 1 comprises the headline and sub-headline and corresponds to the "summary" and "orientation" elements of Labov's model. Move 3 includes "evaluation" and "resolution" elements since their presence in the text is considerably intertwined.

\section{The Summary and Orientation Move: an overview}

The Summary and Orientation move comprises the headline and the sub-headline $^{3}$ of the personal account. While the headline draws attention to the text and summarizes it, the sub-headline functions as a bridge between the headline and the body of a text. It briefly describes what readers can expect from the story. In this way, the headline and the sub-headline intertwine in answering the questions of Labov's "summary" (What is the story about?) and "orientation" (Who, when, where and what?). Hence, they constitute one move - the first one in the "move" structure of the personal account. The Summary and Orientation move aims at introducing an event that arises from the personal experience of the woman telling her story and, by doing so, provides the socio-cultural setting of this genre (the time, place, participants and their interpersonal relations).

The communicative purpose of this move is realized through two rhetorical strategies: 1) voicing the woman telling her story, presented by the headline; and 2) voicing the person who is in charge of the communicative situation, i.e., the editor, manifested by the sub-headline. These two rhetorical strategies have a linear sequence (i. e. reflect the sequence of the headline and the sub-headline) however, they intertwine in accomplishing the communicative purpose of the move. Each involves a number of rhetorical options which are linguistically marked.

\subsection{Headlines of the personal account: voicing the woman telling her story}

The analysis of syntactic and semantic features of headlines of personal accounts has revealed that their rhetoric is oriented towards introducing the woman telling her story 1) as the one who really exists; 2) as an authoritative participant, the one who introduces her experience to a large audience of magazine's readers; 3 ) as a member of the Cosmopolitan community.

The research has shown that the dominant syntactic pattern of the analyzed headlines follows the structure of a simple sentence ( 26 occurrences, $52 \%$ of the corpus) or of a compound/complex one (17 occurrences, $34 \%$ of the corpus):

(1) "I was born without a womb" (July 2014).

(2) "I got revenge on the man who abused me" (January 2007). 
A sentence-type structure allows presenting the summary of the experience in the best suitable way - "who did what, how and where" - and manifests a natural social way of conveying information. It facilitates the comprehension of the topic or the event. The tense form of the verb helps to specify the temporal context of the event. The combination of present and past tenses in complex headlines (example 5,6 ) indicates not only the temporal gap between them but, most importantly, the significance of the events in communicating topical information. The past tense is connected with relatively marginal or circumstantial event whereas the present tense serves a foregrounding function (Chovanec 2003: 90) thus, drawing attention towards the topic of the story. So, the linguistic features of a sentencetype structure indicate the importance of conveying the information in the most comprehensible way.

Minor-sentence types of headlines ( 7 occurrences, $14 \%$ of the corpus) are not typical of personal accounts since they demand some effort in interpreting. However the modification of their head-word provides a focus for the interpretation:

(3) My boyfriend's secret addiction (May 2015).

The noun as the main element of the headline sometimes helps to predict the content of the story but mostly arouses anticipation. In the example above, the possessive pronoun $m y$, the possessive case of the noun boyfriend, and the adjective secret evoke a range of associations concerning the problem of addiction. These modifiers provide certain clues to the story by specifying the subject.

A conspicuous linguistic feature of headlines of the personal account is that of the direct speech (43 instances, $86 \%$ of the corpus). The direct speech of the message makes it sound credible. However, the question of faithfulness and authenticity is not the only at issue; the direct speech provides a "full re-enactment of the speech event" (Urbanová 2012: 41). Being 're-enacted' rather than described, it positions the woman telling her story as a credible participant in the communicative situation of the personal account and, hence, creates an illusion of face-to-face communication:

(4) "Why is it so hard to say, this is my wife?"(March 2015).

(5) "I don't believe in abortion but I thought about it" (April 2007).

(6) "I'm a feminist ... and I got a boob job" (May 2015).

Direct speech of questions (example 4) creates an allusion of reciprocity by presupposing the potential existence of an answer preparing the ground for telling a story. Structures of contrast (example 5) and comparison (example 6) foster a sense of involvement by requiring consideration of certain elements in the system of already known objects and events. For instance, the but-structure (example 5) triggers a situation of conflict, while the unusual combination of notions such as a feminist and a boob job (example 6) forces the reader to compare them and, possibly, reconsider. In other words, the linguistic option for the reported 
speech is oriented towards involving the reader into interaction by establishing present temporal deixis of the communicative situation. It is worth mentioning that there are no directives in the corpus which does not necessarily mean that such headlines do not exist. On the contrary, they are quite popular in women's magazines as effective means of engaging into action (McCracken 1993, Hermes 1995). Their absence in the personal account manifests the importance of participants' equal status in the context of this genre.

The rhetorical potential of the direct speech is supplemented by the utilization of certain lexical items. The most conspicuous of them is the use of the first person pronoun $I$ ( 30 occurrences, $60 \%$ of the corpus) or a noun pre-modified by the possessive pronoun $m y$ ( 14 occurrences, $28 \%$ of the corpus). In both cases, the pronoun denotes the woman telling her story. As Benveniste (1971:218) argues "each $I$ can only be defined by the instance of discourse that contains it". Thus, the pronoun $I$ in the discourse community of The Cosmopolitan and in the context of the personal account defines this woman as a member of The Cosmopolitan community and, consequently, the pronoun my not only implies the referent of the speech but introduces the means of woman's identification, for example, through her relation to a man (as shown in the example 3).

On the one hand, "non-referential with respect to reality" (Benveniste 1971: 218), the pronoun $I / m y$ introduces a statement from the perspective of a unique but single being (i. e. the woman sharing her experience). This does not exclude an alternative point of view and, consequently, implies equal status relations of the participants. On the other hand, again with Benveniste's (1971:220) theory in focus, "I announce himself (herself) as the speaker". In other words, the utilization of this pronoun defines this woman among the others in the community of The Cosmopolitan by virtue of her experience and, more importantly, by claiming her position of sharing it. This pronoun reveals an attempt to construct an authoritative role of this woman in the communicative situation of the personal account - the one who introduces the topic, indicates the event and evaluates its effect.

However, an attempt to flatten the authoritative status of this woman can also be traced in the linguistic features of headlines. The use of topical words and stylistic figures leads to an assumption that she shares the reader's lifeworld knowledge, experience, values, and beliefs:

(7) "My boss sexually harassed me and a jury awarded me \$18 million" (September 2015).

(8) "I saw the signs" (November 2015).

(9) My hidden battle with bulimia (July 2007).

(10) The pants that almost ruined my relationship (September 2015).

Topical words like the informal "boss" in the phrase my boss (example 7) refer to the topic of the story. The semantics of this word implies the relationship of control and command. It indicates the common ground of experience and provides a certain focus for the interpretation. The utilization of alliteration (example 8) 
as well as the use of metaphors (example 9) and metonymies (example 10) foregrounds the evaluative content of the message. The meaning that these stylistic figures convey arises from the evaluation of aspects of an event as good or bad ${ }^{4}$ and presupposes some shared knowledge. For example, given that clothes is an important element of modern woman's image and a powerful device in developing relations, the metonymy pants (example 10) sounds quite natural in the text of the personal account. The use of such linguistic tools reveals an attempt to construct an illusion of shared subjective reality and reduce the distance between the woman telling her story and the reader in the communicative situation of the genre.

Similar is the role of quantifiers. Since it is the context that invests non-quantifying words with a quantifying meaning (Darian 2003: 211), it plays a primary role in the formation of quantifiers. Quantifying sense pervades different parts of speech and indicates an appeal to common values and knowledge:

(11) When you meet the one ... at 13 (July 2014).

(12) "I thought I wanted kids, but not right this second" (December 2015).

(13) "Flamenco makes me feel super-sexy" (August 2007).

The phrase "at 13" (in example 11) brings back memories of school relationship and establishes a very positive and, to some extent, nostalgic emotional atmosphere, whereas the noun second (in example 12) emphasizes urgency of the choice and, thus, creates tension. The adjective super-sexy (in example 13) is eye-catching since it reflects an important area of female interests.

To conclude, the rhetorical strategy of voicing the woman telling her story is manifested by the headline of the personal account and is linguistically marked by such linguistic options: sentence-type structure, the direct speech, the use of personal pronoun $I / m y$, topical lexis, stylistic figures and quantifiers. Their use shows an attempt to introduce the woman as an authoritative participant in the communicative situation of the personal account, however sharing the reader's lifeworld. This constructs their informal and friendly relations within the context of this genre.

\subsection{Sub-headlines of the personal account: Voicing the editor}

The sub-headline of the personal account is a syntactically and semantically independent unit written in the third person singular which makes it different from the headline and the body, based on an I-perspective. Semantically intertwined with the headline, the sub-headline reinforces its rhetorical potential by supplying additional information about the woman telling her story. However, the primary aim of the sub-headline in the context of the personal account is to indicate the presence of a person who is in charge of the communicative situation - the editor. It realizes the second rhetorical strategy of the Summary and Orientation move the strategy of voicing the editor. 
This rhetorical strategy involves voicing the editor in the communicative situation of the personal account as a) a mediator rather than actor; b) an authoritative participant (i. e. introduces the woman sharing her experience, summarizes the event and indicates the time of the interaction); c) a member of the Cosmopolitan community.

The most conspicuous linguistic feature of this strategy is the third person form of narration. "She utterance" refers not to a person actualized in the course of the utterance but to an "objective situation and predicates someone outside the instance itself which can always be provided with an objective reference" Benveniste (1971: 221). Hence, it implies the existence of somebody who takes the role of a mediator, introducing the woman telling her story to a large audience of readers. A journalist, an editor or a group of people involved into the creation of the personal account - all of them personify the Cosmopolitan:

(14) At just 28, Sarah-Jayne Taylor is one of Britain's youngest surrogate mothers. She tells Cosmo why having babies for other people is the greatest gift of all (March 2008).

(15) When Hanna Bouveng's dream job on Wall Street became a degrading nightmare, she worried that no one would take her side over her powerful boss. But she fought back and won big. She tells her harrowing story exclusively to Cosmopolitan (September 2015).

Explicitly voiced in sub-headlines, tells Cosmo (example 14), tells exclusively to Cosmopolitan (example 15), The Cosmopolitan establishes its (her) position as the one who selects the message and delivers it to the audience, thus, claiming the authority.

The prominence of editor's status can be traced through other linguistic peculiarities of the sub-headline. The sub-headline provides some information about the woman telling her story: her name, surname, age, sometimes occupation, place of living, names of children, etc. In this way it defines the " $\mathrm{I} / \mathrm{my}$ " of the headline, reinforcing its credibility:

(16) The headline: "I gave away two babies and I'd do it again"

The sub-headline: At just 28, Sarah-Jayne Taylor is one of Britain's youngest surrogate mothers. She tells Cosmo why having babies for other people is the greatest gift of all (May 2008).

The name, age or place does not, in fact, identify real people since "social deixis refers more to the level of relationship between people than to information" (Levinson 1983: 89). The readers are supposed to believe that the stories and their narrators are real, and that the text is produced by the "I" actor that appears in the text. In this way, the status of the editor is flattened and the authority of the woman telling her story (realized by the rhetoric strategy of the headline, see 6.1.) 
is reinforced. Also, these personal details provide a 'frame' of social deixis (in terms of Levinson 1992) for the participants of the personal account. Such presentation of the woman is vague enough to appeal to a sufficiently wide audience triggering their feeling of community.

The rhetorical strategy of voicing the editor is also marked by the use of the present form of the speech verb: tells, reveals, speaks out, etc.) It indicates present temporal deixis of the communicative situation. The speech-reporting verbs signify the communicative activity and indicate the presence of the speaker (Caldas Couthard 1994: 306). They construct the communicative setting of the personal account within the communicative context of The Cosmopolitan identifying the participants as the members of The Cosmopolitan community. The semantics of such speech-reporting verbs implies symmetric status relations of the participants and informal atmosphere of their communication.

The meaningfulness of the editor's message in introducing the topic of the story or specifying the event reflects her familiarity with the knowledge, experience, attitudes and needs representing the essentials of the world of the reader. It constructs an allusion of their community, evokes a feeling of solidarity and reciprocity. Linguistically, this rhetorical attempt is marked by the utilization of structures of expressive syntax (contrast, comparison, emphatic constructions, inversion, questions etc.):

(17) Many people assume rape involves a violent encounter with a stranger, but for thousands of women that's not the case. Tanya Smyth tells Cosmo how she was forced into sex by a man who was almost her boyfriend (June 2008).

(18) Just $3 \%$ of us stick with our first love. Giovanna Fletcher (married to Tom from McFly) tells about defying the statistics - and the cynics ...(July 2014).

(19) How do you find the strength to recover after a vicious rape and then a terrorist attack? Rachel North, 36, had her sister Savannah and her best friend Jane to help her through (August 2008).

The use of but-clauses (Many people assume ... but), emphatic constructions (Just 3\% of us) or inversion (As a kid) draws reader's attention to some important details of the story which appeal to the interests and values of the reader and emphasize the significance or, in terms of Labov (1972), the "reportability" of the event. Questions facilitate understanding of the topic by focusing on a certain aspect of it, they create an allusion of face-to-face-communication -spontaneous, friendly conversation. The absence of directives in the analyzed corpus of subheadlines emphasizes the importance of equal status relations of the participants in the context of this genre (as it was already mentioned in Section 6.1).

Similar is the role of pronouns you or we/us and features of informal language. With reference to the reader, second person you (example 19) simulates interpersonal communication, in which "I" (the combination of the woman telling her 
story and the editor) speaks to "you" (Cosmopolitan's reader) who, by reading this personal account, is supposed to be or become a part of the community of The Cosmopolitan. The inclusive us (example 18) signifies that readers are included in the referential scope of the pronoun and trigger a feeling of community and solidarity. The utilization of these pronouns demonstrates an attempt to positions the editor closer to the reader by emphasizing their common subjective reality.

Informal language defines the speech of the youth - the presumptive audience of the Cosmopolitan. The use of features of informal language to voice the editor presents her as a member of this audience. The informal and colloquial expressions construct a friendly atmosphere for revealing personal, intimate information:

(20) Think you have to be an insider to get anywhere in fashion? This is the story of how Marissa Webb went from an orphanage in Korea to leading the design vision at Banana Republic (May 2015).

(21) When you're diagnosed with a rare cancer at 25 , everyone wants you to spout happy thoughts and sing "Kumbayah". Screw that. Cosmo beauty editor Deanna Pai is pissed off and owning it. (April 2015).

The elliptic structure of the question Think you have to be an insider (example 20), the contraction you're and informal expressions spout thoughts, screw that, pissed off (example 21) in voicing the editor signal easygoing relations of the participants.

To sum up, the rhetorical strategy of voicing the editor is realized by such linguistic tools as the third person form of narration, the present form of the speech verb, the elements of social deixis and informal and colloquial features. These linguistic means are employed to display a friendly atmosphere of solidarity, reciprocity and commonsensical agreement.

\section{Discussion and Conclusions}

This research has shown that, although the headline and the sub-headline of the personal account in The Cosmopolitan are two syntactically and semantically independent units, they both aim at fulfilling the function of "summary" and "orientation" elements of Labov's narrative model and, thus, are defined as one move - the Summary and Orientation, the first one in the generic structure of the personal account. The communicative purpose of this move is to introduce an event arising from the personal experience of the woman and, by doing so, provide the socio-cultural setting of this genre. This communicative purpose is realized via two rhetorical strategies (i.e., two steps) which develop a certain pattern of organization of the move's content. The schematic structure of this move is suggested in Table 2 . 
Table 2. The schematic structure of the Summary and Orientation move of the personal account

\begin{tabular}{|c|c|c|}
\hline $\begin{array}{c}\text { Element } \\
\text { of genre's } \\
\text { textual } \\
\text { structure }\end{array}$ & $\begin{array}{c}\text { Schematic structure } \\
\text { of the Summary and Orientation move }\end{array}$ & Key linguistic features \\
\hline Headline & $\begin{array}{l}\text { Step 1: voicing the woman telling her } \\
\text { story } \\
\text { Step 1a as the one who really exists; } \\
\text { Step 1b as an authoritative participant; } \\
\text { Step 1c as a member of the Cosmo- } \\
\\
\text { politan community. }\end{array}$ & $\begin{array}{l}\text { - Sentence-type structure of } \\
\text { the headline; } \\
\text { - Direct speech; } \\
\text { - Personal pronoun I/my; } \\
\text { - Topical words, stylistic } \\
\text { figures, quantifiers and } \\
\text { intensifiers. }\end{array}$ \\
\hline $\begin{array}{l}\text { Sub-head- } \\
\quad \text { line }\end{array}$ & $\begin{array}{l}\text { Step 2: voicing the editor } \\
\text { Step 2a: as an authoritative mediator } \\
\text { rather than actor; } \\
\text { Step 2b as a member of the Cosmo- } \\
\\
\text { politan community. }\end{array}$ & $\begin{array}{l}\text { - Third person form of nar- } \\
\text { rative; } \\
\text { - Elements of social deixis; } \\
\text { - Speech-reporting verbs; } \\
\text { - Expressive syntax } \\
\text { - Use of the personal pro- } \\
\text { noun you/inclusive we; } \\
\text { - Informal language. }\end{array}$ \\
\hline
\end{tabular}

The table shows that the content of the Summary and Orientation move is organized in the linear sequence of two steps: voicing the woman telling her story and voicing the editor of the personal account. The first step corresponds to the headline, whereas the second - to the sub-headline. The rhetorical preferences of each step are marked by the key linguistic features of a corresponding textual element.

Step 1 voices the woman telling her story as a credible and friendly participant awarded with an authoritative status due to her will to share the experience. The option for the first person form of direct speech in the headline reveals an attempt to solicit the atmosphere of privacy and reliance. The sentence-type structure of the headline facilitates the comprehension of the information and reflects a familiar way of conveying the message. The use of topical words, stylistic figures, intensifiers and quantifiers is oriented towards demonstrating that she shares the reader's lifeworld soliciting a feeling of community and, hence, an appropriate interpretation of the information.

Step 2 voices the editor in charge of the personal account. The third person narrative provides the evidence for the journalist's presence, whereas other elements of the genre's textual structure (written in the first person) position the editor as a mediator and provide more authority to the woman telling her story. The prominence of the editor in the communicative situation of the personal account is established by positioning her as the one who introduces the woman telling her story and indicates the temporal deixis of the communicative situation. The use 
of pronouns, structures of expressive syntax and informal language is oriented towards triggering a feeling of community and creating informal atmosphere of reciprocity.

In general, by means of both rhetorical strategies, the ' $I$ ' of the personal account is constructed by a combination of two voices, that of the woman telling her personal story, and that of the editor in charge of the personal account. Influenced by the editor's voice, position and institutional points of view, the woman sharing her experience is presented as an authority. However, the informal and friendly relations of the participants constructed by means of this move flatten this status and position her as a member of the magazine's community. The event is introduced as a manifestation of the specific vision of situations commonly faced by women and serves as a strategic beacon for the preferred estimation of typical situations and the evidence for the shared reality. The structure of the move meets readers' expectations in a sufficiently satisfying way and helps to build a loyal readership that tends to accept the ideas inscribed in the texts of the genre.

This research has shown that although the Summary and Orientation move is realized by two different textual elements of the personal account, they mutually aim at constructing a socio-cultural setting of this genre within the community of the magazine by 1) defining its participants as the members of community; 2) establishing their relations of trust, solidarity and friendship; 3 ) indicating the topic of their potential interest. Such a threefold orientation of this move defines its highly important role in the generic structure of personal accounts as that of a powerful mechanism providing unconscious and uncritical acceptance of the ideas encoded in the texts of this genre.

This study has demonstrated that the analysis of structural and semantic organization of a single move can be useful in understanding how the information is coded in the media genre. The personal account is endemic in women's magazines, and the understanding of its rhetorical techniques can be useful both to producers and consumers of such texts. Female readers are knowledgeable and active participants in the experience of storytelling and, thus, should be aware of the functional mechanism of the personal account before they agree to accept the ideology of femaleness promoted by women's magazines today.

The model of this move can be regarded as a basis in the personal account genre research and may be adopted not only to determine its distinctive features but also to map creative changes and executions that stretch and exploit its potential. Likewise, the model can be useful to journalist practitioners in their writing skills training.

Further research is needed to analyze other moves of the genre: Complicating Actions, Resolution and Evaluation, and Coda as well as the generic structure of other genres of modern media discourse. The studies can contribute not only to the spheres of media studies, genre studies and media-ecology but also to the domain of written discourse for applied needs. 


\section{Notes}

1 For an extensive literature review, see, e.g., Cameron (2005).

2 The personal account is a type of an unstructured or non-directive interview, considered to be the opposite of a structural interview, which offers a set amount of standardized questions. For more details, see Rubin (2005).

3 A sub-headline (also sub-heading, sub-title or deck in journalism jargon) is a subordinate title under the main headline. It is situated below the headline and precedes the main text, written either in bold or in a different from the headline and the body color. It functions as a summary of the text, i.e. briefly informs the reader about the content of the article. Retrieved from https://en.wikipedia.org/wiki/News_style (accessed on 15 September 2015).

$4 \quad$ For more information on how speakers can evaluate aspects of the world, see, e.g., Bednarek (2006).

\section{References}

Ballaster, Ros, Beetham, Margaret, Frazer, Elizabeth and Hebron, Sandra (1991) Women's Worlds. London: Macmillan.

Bednarek, Monika (2006) Evaluation in Media Discourse: Analysis of a Newspaper Corpus. London: Continuum.

Benveniste, Emile (1971) 'The nature of pronouns'. In: Problems in General linguistics. Translated by Mary Elizabeth Meek. Miami: Miami University Press, 217-222.

Bhatia, Vijay (2004) Worlds of Written Discourse - A Genre-Based View. London and New York: Continuum.

Bruner, Jerome (2004) 'Life as narrative'. Social Research 71(3), 691-710.

Caldas-Coulthard, Carmen Rosa (1994) 'On reporting reporting: the presentation of speech in factual and factional narratives'. In: Malcolm Coulthard (ed.) Advances in Written Text Analysis. London: Routledge, 295-308.

Caldas-Coulthard, Carmen (1996) “"Women who pay for sex. And enjoy it”: Transgression versus morality in women's magazines'. In: Carmen Caldas-Coulthard, Rosa and Malcolm Coulthard (eds.) Text and Practices: Readings in Critical Discourse Analysis. London: Routledge, 250-270.

Cameron, Deborah (2005) 'Language, gender, and sexuality: Current issues and new directions'. Applied Linguistics 26(4), 482-502.

Chovanec, Jan (2003) 'The uses of the present tense in headlines'. Theory and Practice in English Studies, Volume 1. Brno: Masaryk University, 83-92.

Craviotto del-Teso, Marisol (2006) 'Words that matter: Lexical choice and gender ideologies in women's magazines'. Journal of Pragmatics 38, 2003-2021.

Darian, Steven (2003) 'The language of quantifying'. In: Steven Darian Understanding the Language of Science. Austin: University of Texas Press, 201-250.

Ferguson, Marjory (1983) Forever Feminine: Women's Magazines and the Cult of Femininity. London: Heinemann.

Figueiredo, Debora (2009) 'Narrative and identity formation: an analysis of media personal accounts from patients of cosmetic plastic surgery'. In: Bazerman, Charles, Adair Bonini and Debora Figueiredo (eds.) Genre in a Changing World. Fort Collins, CO: WAC Clearinghouse, 255-276.

Hermes, Joke (1995) Reading Women's Magazines. Cambridge: Polity Press.

Labov, William (1972) Language in the Inner City. University Park: University of Pennsylvania Press.

Levinson, Stephen (1983) Pragmatics. Cambridge: Cambridge University Press. 
Machin, David and Thornborrow Joanna (2003) 'Branding and discourse: The case of Cosmopolitan'. Discourse and Society 14(4), 453-471.

Martin, James (1985) Factual Writing: Exploring and Challenging Social Reality. Geelong, Vic.: Deakin University Press.

McCracken, Ellen (1993) Decoding Women's Magazines: From Mademoiselle to MS. London: Macmillan.

Miller, Carolyn (1994) 'Genre as social action'. In: Freedman, Aviva and Peter Medway (eds.) Genre and the New Rhetoric. Bristol: Taylor and Francis, 23-42.

Rubin, Herbert (2005) Qualitative Interviewing: The Art of Hearing Data. Beverly Hills: Sage.

Segal, Judy (2007) 'Breast cancer narratives as public rhetoric: Genre itself and the maintenance of ignorance'. Linguistics and the Human Sciences 3(1), 3-23.

Swales, John (1990) Genre Analysis: English in Academic and Research Settings. Cambridge: Cambridge University Press.

Tomášková, Renáta (2009) 'Communication Strategies in Women's and Men's magazines'. In: Hopkinson, Christopher, Lenka Sedlářová, Renáta Tomášková, Sirma Wilamová and Gabriela Zapletalová (eds.) Communication Strategies in Texts and Talk. Ostrava: Faculty of Arts, University of Ostrava, 75-129.

Urbanová, Zuzana (2012) 'Direct and indirect forms of representation in the discourse of newspaper reports: Less frequent phenomena'. Brno Studies in English 38(1), 39-54.

Whinship, Janice (1987) Inside Women's Magazines. London: Routledge.

Yakhontova, Tatyana (1997) 'Bakhtin at home and abroad'. JAC: A Journal of Composition Theory 17(1), 83-94.

\section{Sources}

Cosmopolitan US July 2014. Available from http://read-magazines.com/brand/cosmopolitan (accessed on 20 August 2015).

Cosmopolitan US September 2014. Available from http://read-magazines.com/brand/cosmopolitan (accessed on 20 August 2015).

Cosmopolitan US March 2015. Available from http://read-magazines.com/brand/cosmopolitan (accessed on 20 August 2015).

Cosmopolitan US April 2015. Available from http://read-magazines.com/brand/cosmopolitan (accessed on 20 August 2015).

Cosmopolitan US May 2015. Available from http://read-magazines.com/brand/cosmopolitan (accessed on 20 August 2015).

Cosmopolitan US September 2015. Available from http://read-magazines.com/brand/cosmopolitan (accessed on 22 December 2015).

Cosmopolitan US November 2015. Available from http://read-magazines.com/brand/cosmopolitan (accessed on 22 December 2015).

Cosmopolitan US December 2015. Available from http://read-magazines.com/brand/cosmopolitan (accessed on 22 December 2015).

Cosmopolitan UK January 2007: 103-113. Print.

Cosmopolitan UK April 2007: 98-100. Print.

Cosmopolitan UK July 2007: 121-122. Print.

Cosmopolitan UK August 2007: 167. Print.

Cosmopolitan UK March 2008: 114. 124-125. Print.

Cosmopolitan UK May 2008: 77-78. Print.

Cosmopolitan UK June 2008: 123. Print.

Cosmopolitan UK August 2008: 90. Print. 
Halyna Kryzhanivska received her Ph.D. in English and Linguistics from Ivan Franko National University of Lviv in 2011. Currently, she is an Associate Professor of the Department of Foreign Languages for Sciences. She has been teaching ESP courses for 15 years at the same department. The scope of her scientific interests lies within the field of applied linguistics, namely discourse and genre analyses, media studies, and functional linguistics. Halyna has published two textbooks and 15 papers in Ukrainian scientific journals. Her latest publications are focused on pragmatic aspects of media discourse.

Address: Halyna Kryzhanivska, Department of Foreign Languages for Sciences, Ivan Franko National University of Lviv, 1 Universytetska str. 79000 Lviv, Ukraine. [e-mail: h.kryzhanivska@ gmail.com]. 